\title{
An Analysis of the Use of Graphs in People's Daily Life
}

\section{Un análisis de los usos de las gráficas en el cotidiano de la gente}

\section{Uma análise dos usos dos gráficos no cotidiano das pessoas}

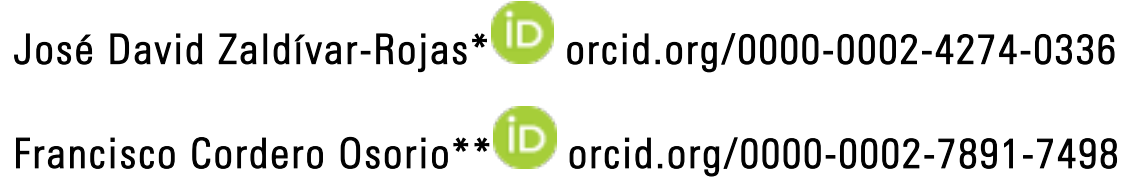

\section{Para citar este artículo}

Zaldívar-Rojas, J. y Cordero Osorio, F. (2021). An Analysis of the Use of Graphs in People's Daily Life. Revista Colombiana de Educación, 1(83), 1-22. https://doi.org/10.17227/rce.num83-10608.

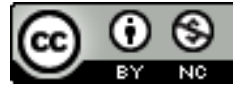

* Doctor en Ciencias con especialidad en Matemática Educativa. Profesor de la Universidad Autónoma de Coahuila: Saltillo, Coahuila, MX. Correo: david.zaldivar@uadec.edu.mx

* Doctor en Ciencias con especialidad en Matemática Educativa. Profesor Centro de Investigación y de Estudios Avanzados del Instituto Politécnico Nacional. Correo: fcordero@cinvestav.mx 


\section{Abstract}

Keywords: mathematics education; nonformal

education; graphs; graphing calculators; social theories; use studies
This research paper addresses the lack of connection between people's own knowledge and the use of mathematical functions and scholastic mathematics. Experts in the field acknowledge that this issue generates a phenomenon of opacity in people's daily lives and the use of mathematical knowledge. Put in other words, other mathematical social functions, apart from those utilized in school environments, are not considered. To highlight this phenomenon, empirical evidence is built from the analysis of cultural forms of knowledge concerning the use of graphs in a setting of movement. Such evidence is overshadowed by scholastic mathematics, due to that fact that the foresaid forms are immersed in nonconventional argumentations. A reference framework of the use of graphs that resignifies trajectoryand curvethen arises. In this framework, the search for permanence and invariants when things vary gives way to the very argumentation of one's own mathematical knowledge that is, however, obscured in scholastic mathematics.

\section{Resumen}

\section{Palabras clave: matemática educativa; educación no- \\ formal; gráficas; calculadoras graficadoras; teoría social;} estudios de uso
En el presente artículo se aborda como problemática la ausencia de diálogo entre los saberes de la gente y la matemática escolar. Se afirma que esto da lugar a un fenómeno de opacidad del cotidiano de la gente y sus usos de conocimiento matemático; esto es, no se consideran otras funciones sociales del conocimiento matemático en escenarios diferentes al escolar. Para evidenciar dicho fenómeno, se construye evidencia empírica a partir del análisis de formas culturales de saberes relativas al uso de las gráficas en una situación de movimiento. Sin embargo, la matemática escolar opaca tal evidencia, debido a que dichas formas se encuentran en argumentaciones no convencionales. Se conforma así un marco de referencia del uso de la gráfica que resignifica la trayectoria y la curva, y donde la búsqueda de la permanencia y de invariantes en las cosas que varían conforma la argumentación propia de los saberes matemáticos de la gente, aunque se ve opacada en la matemática escolar.

\section{Resumo}

\author{
Palavras-chave: matemática \\ educacional; educação não \\ formal; gráficos; calculadoras \\ gráficas; teoria social; \\ estudos de uso
}

Neste artigo, a ausência de diálogo entre saberes populares e a matemática da escola, são abordadas como uma problemática. Afirma-se que o exposto, gera um fenômeno de opacidade em relação ao conhecimento matemático na cotidianidade, na medida em que, outras funções sociais deste conhecimento não são consideradas em cenários diferentes da escola. Para evidenciar esse fenômeno, a evidência empírica é trabalhada e desenvolvida em uma análise de formas culturais relacionadas ao uso de gráficos matemáticos implementados em uma situação de movimento. No entanto, a matemática da escola turva tal evidência, porque essas formas são encontradas em argumentos não convencionais. Assim, forma-se um quadro de referência para o uso do gráfico que ressignifica a trajetória e a curva, onde a busca de permanência e de invariáveis nas coisas que variam, formando a argumentação própria dos conhecimentos matemáticos populares, embora, estes sejam ofuscados pela matemática da escola. 


\section{Introduction}

A review of investigations focused on the role of students' everyday knowledge in the construction of mathematical ideas in school was conducted to pinpoint the problem in the lack of connection between students' perceivable knowledge and scholastic mathematics addressed in this paper. The purpose is to enhance considerations on such issue, which suggest that the number of years of schooling does not guarantee that the mathematics used outside of school environments and daily life is parallel to what is learned in the classroom (Arnay, 1997; Cantoral, 2013).

In general terms, the value of scholastic mathematics in use is quite distant from what is used in the context of students' daily lives. This poses that almost all knowledge developed in school is utilitarian and applicable only under conditions similar to those in which it was developed (Cantoral \& Farfán, 2003; Buendía \& Cordero, 2005; Cordero, 2008; Nunes et al., 1991; Lave, 1988; Arnay, 1997). The school mathematics discourse (sMd ${ }^{1}$ ) that norms school mathematics (Soto \& Cantoral, 2014) promotes an epistemological "monumentality" of the school curriculum in which knowledge appears crushed and "sanctified". Students can only expect to "cover" it, or perhaps enjoy it, although they have no idea of its reason for being (raison d'être) (Chevallard, 2013). Furthermore, the sMd perpetuates the hegemonic vision that nullifies any manifestation of knowledge that differs from the established (Cordero et al., 2015). Everyday knowledge is among these manifestations.

Paradoxically, the school curriculum of mathematics argues in favor of the integration of students' everyday knowledge in teaching and learning scholastic mathematical knowledge. This dual relationship is the focal point of this paper in view of the fact that considering this relationship as a simple transference problem (Lave, 1988) involves phenomena connected with the function of daily knowledge in the structure of scholastic mathematics. For example, and firstly, in some inquiries, everyday knowledge is considered a synonym of erroneous knowledge that should be nullified by school knowledge (Arnay, 1997; Rodrigo, 1997). Secondly, the only function of students' daily knowledge is pedagogical, and its only interest is in teaching and education and should be formalized; however, it is not rightfully considered a proper form of knowledge or to have epistemological value.

In this regard, the issue of everyday knowledge goes beyond "formal" or "informal" education by drawing attention upon how people, as well as their ways of using mathematical knowledge, have been ignored in the sMd. People does not only make reference to "a set of persons". People are assumed to be an essential element of mathematical knowledge construction to make that which is specific of and intimate in given communities, minorities, scientific disciplines, professions, and daily life visible and vindicate.

The next section addresses this topic and characterizes a theoretical-methodological framework to approach it.

1 This notion comes from the Socioespistemological Theory and refers to the set of ideas that validate the introduction of mathematical knowledge to educational systems and that legitimize a new system of reasoning (Cantoral et al., 2018, p. 79). It has to do with setting up of communication bases for the formation of consensus and the construction of shared mathematical meanings, affecting the relationship between students and teachers (Soto \& Cantoral, 2014). 


\section{The Matter at Hand}

Several studies warn that mathematical knowledge is presented as labeled and polarized, and stands a hierarchy and continuity among science, teaching and daily practice (Lave, 1988). Some investigations consider the role that everyday mathematics (as in Anglo-Saxon tradition) plays in school practices, despite the negative connotations of the label "everyday". For this purpose, they claim that it is possible to analyze scholastic mathematics by bringing to the school setting: (a) the objects of study in everyday mathematics, (b) social organization aspects in non-scholar settings (for example: collaborative work), (c) discourse practices of work settings and/or (d) participation structures of everyday activities such as discussion, conversation or debate (Civil, 2002; Moschkovich, 2002). As can be appreciated in these cases, everyday seems to have a connotation of prior, and something that is non-scholar, but with the possibility of being used and formalized through education. Hence, it seems that school knowledge is a "natural" sequel of what students already knew. In other words, this means going from simple to complex, from informal to formal and from beliefs to scientific.

Now, some approaches consider everyday knowledge proper knowledge and not in terms of its condition of prior or erroneous. It is understood as Implicit theories or Alternative conceptions. Such theories or conceptions can be characterized as emotional experiences that people build around their reality or experiences (Rodrigo, 1997; Slater et al., 2018). These studies assume that being unaware of the nature of everyday knowledge results in its trivialization and devaluation in school settings. Such condition reflects inconsistencies in its consideration in the construction of school knowledge and its relationship with scientific knowledge (Arnay, 1997), as well as in its inclusion in learning experiences not related to students' previous experiences. For those who share these beliefs, everyday knowledge comes from a cognitive dimension which creates representations in specific settings. Consequently, they postulate an individual episodic construction of knowledge. These studies are guided by constructivist approaches to knowledge and the importance of the cognitive subject, so everyday life is only considered from a personal point of view.

Other types of investigations analyzed how mathematics lives in non-scholar settings. For example, the work of nurses or woodworkers, or when a scientific development is addressed in specific disciplines, or in daily activities (see the works of Hoyles et al., 2001; Lave, 1988; Nunes et al., 1993; Pozzi et al., 1998; Tuyub \& Cantoral, 2012). These investigations do not focus on the learning of a specific mathematical concept, but on highlighting the importance of the setting and the different ways in which knowledge is set to work less visibly in certain situations. Their purpose is to characterize the nature of the mathematics used in non-scholar settings more locally, highlighting the characteristics of the human activity and the individuals as part of study groups that share actions, activities, and practices.

This review identifies everyday knowledge and its inclusion in the didactic system, which is synthesized in the social function conferred to that knowledge. It is important to establish that everyday knowledge should not only respond to cognitive aspects and focus on individuals, but it brings up its processes of construction and manifests itself collectively among people who do not seem to be taken into consideration. From this point of view, the problems concerning everyday knowledge go beyond pedagogical and formalization implications. It is a more thorough criticism of the model that supports the smd related to (a) an object-centered perspective (Cantoral, 2013) that reproduces an opacity phenomenon of people's knowledge in scholastic mathematics (Cordero et al., 2015). This means that the smd and its 
establishment obscure how people use their knowledge to deal with daily life situations that could have a social function different from those established in the school.

The discussion on everyday knowledge -considered as knowledge in use and related to the knowledge of people- implies an epistemological and ontological position in relation to phenomena associated to the teaching and learning of mathematics. This reasoning enhances a broader vision of different settings, to understand how mathematics is used in non-scholar situations, and the function everyday knowledge has in the teaching and learning processes in the school, so that it could be possible to comprehend school knowledge supported by the learner's reality (Cantoral, 2013). This approach assumes, from the beginning, that everyday life is a valid and genuine knowledge that coexists and relates to scholastic mathematical knowledge, but with a specific epistemology and a situated context related to the use of knowledge in a specific situation. Therefore, it is characterized as everyday knowledge because it expresses the obscured knowledge of people in scholastic mathematics (Zaldívar, 2014).

The former discussion is a turning point in the cognitive positions centered on individuality and the abilities of students as cognitive subjects (Radford, 2013). This means considering the users rather than avoiding the focus on the analysis of mathematical objects (MO) isolated from the situations that gave them sense and meaning. The mo are placed in a situated and social context; that is to say, as knowledge that emerges from the constant and reflexive exercise of certain social practices ${ }^{2}$ (SP) which give rise to those objects and their relationships (Buendía \& Cordero, 2005). This is what we call positioning in the social construction of mathematical knowledge (SCMK) from the socioepistemology theory (ST).

This positioning not only signifies a descentralization of the object (Cantoral, 2013), It also implies a methodological choice because recognizing those SP enriches the analysis of the phenomena associated with the relationships between mathematical knowledge and thinking, knowledge and culture ${ }^{3}$. Focusing on the SCMK enhances the discussion on the conditions of production of mathematical knowledge in non-scholar settings to understand and promote interventions and redesigns of the sMd. This redesign is focused on the functional aspects of knowledge to transform the didactical system (Cordero, 2008). The ST proposes the use of systemic and multiple approaches to deal with the didactic phenomena related to the development of mathematical thinking. It recognizes the integration of the epistemology of knowledge, its socio-cultural dimension, the cognitive processes associated, and the institutionalizing mechanisms in teaching, based on research studies (Cantoral \& Farfán, 2013). Therefore, the research program of the ST allows for the relativism of the concepts and processes of mathematics because it accepts that knowledge operates in a situational way

2 The theoretical approach (ST) assumes social practices as the actions of a social group that has its own meanings and intentions, is located in a historical context or a current one, acts in accordance with prevailing ideologies, and uses mathematics as a tool for building knowledge. [...] Our intention is that students can achieve a school mathematics knowledge which is truly functional, that is a knowledge which is integrated into their own lives, transforming and giving them new meanings. (Buendía \& Montiel, 2011, p. 68)

3 In the theoretical framework, it is assumed that SP allow establishing the norms of social functioning (normative function) (Soto \& Cantoral, 2014). So, the study of the SCMK occurs in the uses of mathematical knowledge under specific situations, focused on the elements coming from the community under study, not only on the mathematical objects themselves. It is then considered that the practices should be the basis for the reorganization of the mathematical work and the redesign of the smd (Buendía \& Cordero, 2005). In this sense, it is considered that the analyses are enriched since they do not focus only on the cognitive aspects of the mental constructions made by the participants. Instead, the change from the mathematical object to the practiceallows establishing the functionality of mathematical knowledge through redefinitions associated with the use of knowledge in a specific situation in which the latter is based on an epistemology of practices. 


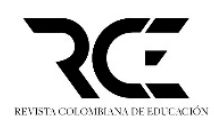

and attends to social functions that differ from the curricula. In brief, the st recognizes the validity of every type of knowledge defined collectively and which exists in culture or society.

The goal of the following sections is to characterize the function of people's daily lives and their relationship with the construction of mathematical notions to build a reference framework which gives new meaning to those notions in scholastic mathematics.

\section{Theoretical elements}

The ST assumes that mathematical knowledge is constructed socially. So, its introduction to the didactic system compels to a series of transformations that affect its structure, as well as the relationships between teachers and students. It also must be recognized that mathematical knowledge is a tool used in different contexts, that is to say, that it "lives" through actions in human activity (Cantoral et al., 2018). In other words, that mathematics has meaning through its use (Cantoral, 2013). Such use shows the function of social practices while engaged in the social construction of knowledge. This social dimension reveals how individuals or communities relate to the object of study, and how it is resignified not only through its use, but also by the culture, meanings and shared procedures elaborated in specific situations under certain institutional procedures (Cordero, 2008; 2016).

Additionally, the works of Berger \& Luckmann (1991) explain the reality of daily life and its associated process, such as institutionalization and socialization. According to these authors, daily life is the most visible and identifiable image of reality. Their central thesis is that reality is a social construction, so they focused on drawing the processes of socialization by which a body of knowledge becomes "reality". As a consequence, the authors divided daily life into sectors. On one end of the spectrum is daily life, seized by routines and maintained under similar conditions. On the other end is daily life presented as different types of problems that lead to maintenance crisis. Therefore, daily life is expressed in terms of routine, maintenance and its crisis, naturalness, practicality, transparency, a-systematically and accessibility. It has its own historical and cultural character because routines are maintained or preserved for some time as they develop or regress. In brief, these authors present an epistemology for the knowledge of daily life under institutional dimensions that can be established as a social construction mechanism based on a dialectic maintenance-crisis (see Figure 1).

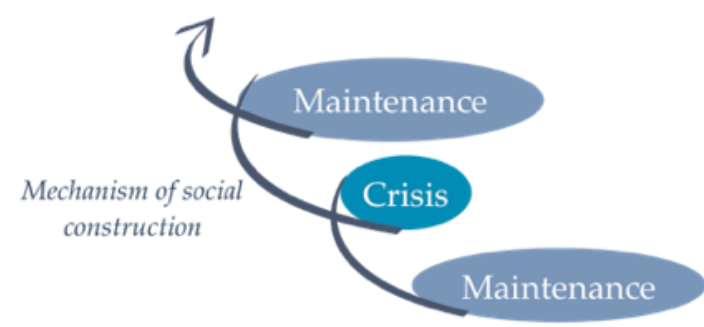

Figure 1. Mechanism for maintenance and crisis of routines Source: Own elaboration 
Based on a reinterpretation of the previous notions from the ST, and highlighting that everyday knowledge is a category that expresses functional everyday knowledge, it is considered that the dialectic maintenance-crisis procedure characterizes an epistemology for everyday life in terms of knowledge in specific situations. In this way, daily life refers to certain cultural forms of knowledge that were socially and historically present in different areas of human activity that are maintained in a specific situation but susceptible to transformation (Zaldívar, 2014).

Given the position assumed in this investigation, the ST postulates that human activity can be described in terms of social practices expressed in a minimum unit of analysis: the use of knowledge. From the results of Cordero (2008) and Cordero et al. (2010) the use of mathematical knowledge is characterized with reference to two dialectic elements: functionality (Fu) and form (Fo); what is done and how it is done, respectively. In brief, the use of knowledge expresses actions, explanations, significations, and executions of what is done in conjunction with how it is done, namely procedures and arguments in which the important thing is where it is used and under what institutional conditions. Functionality and form are a pair of theoretical elements in which the use of mathematical knowledge can be recognized and also express the development of the use in new situations. This emergence of development is named resignification.

The notion of resignification expresses the use of mathematical knowledge of groups and communities because the goal is to leave the object-centered perspective and focus on the Argumentations of the mathematical objects (Arg[Mo]), which can be achieved with the intentional use of these objects under specific circumstances ${ }^{4}$.

Hence, it is possible to characterize the function of people's daily lives in three vectors: (1) an epistemology based on the social construction mechanism which is developed as maintenance and crisis argumentations, which has way through the intentional use of mathematics; (2) a sociocultural and institutional setting which is defined in a specific situation that presents functional mathematics, and (3) a construction process of resignification in terms of the development of argumentations and Fu-Fo (see Figure 2).

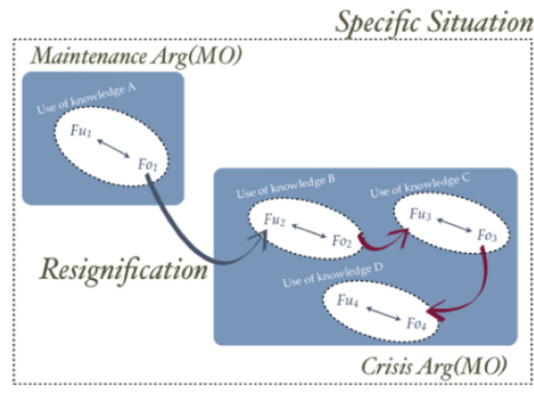

Figure 2. Model for the analysis of daily life of the citizen Source: Own elaboration

4 In the work of Suárez and Cordero (2010) the dyad Fu-Fo is used to express the development of the use of the graph made in the works of Nicolás Oresme regarding the study of variational situations. In his works, Oresme became interested in understanding the phenomena of variation through figures, which in his time meant an unprecedented use of graphics. So, in Oresme's work an alternative use of graphs is proposed to understand phenomena (Fu). For this purpose, a new way of using graphs is established, consisting in assigning measures to the physical variables through segments (Fo). This is evidence of a resignification of an old paradigm regarding the use of graphics. 
Therefore, the purpose of this study is to show the argumentations and uses of knowledge obscured by the smd, so that everyday knowledge could become an element to consider in its redesign. The following sections will show an example based on the use of graphs in a specific setting.

\section{Methodological Considerations}

Due to the social nature of this research, it was pertinent to expand the vision and consider an ideal setting that did not limit discussion about the group and their knowledge. Thus, a thematic workshop in a communicating science (cs) setting was selected to build the empirical evidence. Research recognizes the role of cs to raise dialog between science and not necessarily scientific people through socialization. It enables the presence of science in people's culture without any attempt to become a "substitute class" (Roqueplo, 1974).

Three axes justify the insertion in a cs scenario: the socialization of knowledge, scientific enculturation, and the not necessarily scientific population. The first element, socialization, refers to the fact that the dissemination of science plays an important political role in the development of science since it allows all people to make decisions within the powers of science. The second axis implies that being a participant in a communicating science scenario will not necessarily make people scientists, but it does achieve something, a certain presence of science in people's culture. Lastly, it is recognized that those attending this type of program are social actors immersed in a specific society and in continuous relationship with others. Put differently, they are historical subjects ${ }^{5}$ involved in extremely varied scenarios.

Thematic workshops were implemented to build the empirical evidence. The experimental tool considered was a situation named the spring. It focuses on the movement of a mass connected to a spring to enhance discussion on the conditions and elements, such as trends, involved in this situation, giving preference to visualization and the work performed with specific devices.

\section{The Spring Situation: Theoretical Foundations and A Priori Analysis}

The design of the spring situation takes into consideration the functional elements of mathematical knowledge and problematizes the notion of Cartesian graphs. This situation is based on modeling movement situations using graphs, known as modeling-graph category (MG) (Suárez \& Cordero, 2010) which emphasizes the use of a graph and the trend behavior. Therefore, the activities proposed are not expressed as a mathematical problem which has to

5 The main idea when reflecting on the notion of the subject is to consider it only from a cognitive or epistemic dimension, that is, as a subject that is always available to learning and the development of its reasoning. This notion of the subject is found, for example, in the Piagetian or constructivist tradition. However, given the socio-cultural position assumed in our research, our notion of the subject is far from this cognitive or epistemic subject. It is considered a notion of subject more in line with historical-cultural positions (Radford, 2019). It is rather a social subject, reflective and located in a well-defined historical period and participant of a community. The subject is considered historically and culturally situated in a diversified social reality, that is to say, a subject as much as its community. In the words of Radford (2019), "individuals of flesh and blood, individuals who breathe, sweat, suffer, and enjoy." 
be solved in an analytical or geometrical way. It is an experimental situation which produces arguments related to the behavior of the trends in the graphs of the resulting functions (Cordero, 2016). It is important to identify that this experimental situation implies moving away from the object-centered perspective because it places variation, the behavior of trends, and the discussion of a system of reference as its arguments and promotes the manifestation of the use of graphs.

Having stated the above, the spring situation addresses properties of the mass-springcushioning system, such as trend and asymptotic behavior over time. Therefore, the references to the asymptotic conditions of the system are situational through the behavior and reading of graphs generated by movement sensors (calculator-based ranger [CBR]) (see Figure 3 ), or from the results of the interaction between the spring and the weight produced by the participants during the workshop.

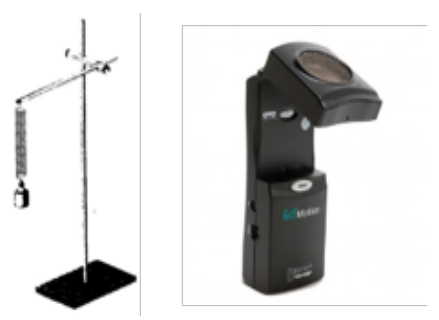

Figure 3. The experimental setup and the CBR Source: Zaldívar (2014)

There are three established moments in this situation: (I) maintenance, (II) crisis, and (III) functionality. The first moment questions the participants of the workshop on the movement of the spring when a weight is placed at one end. They were asked to draw this movement. The aim of this moment and the task related to it is to get the first arguments of the participants about movement and the recognition of special features with regards to the phenomenon that was presented.

During the second moment, crisis, the participants were asked if the spring stopped or not, and how it was possible to see this information in their productions. At this moment, they were also asked about variation and system trends. Here, the aim is for students to realize that there might be some aspects of the phenomenon that need to be taken into account, for example if the spring would ever stop. The main goal of the remaining questions was to problematize the first productions of the participants, and determine whether or not they considered non-explicit elements of the phenomenon, such as speed and tendency.

Lastly, the third moment enhances questions and insights about the trend of the movement of the spring and the initial conditions of the graph which represent that movement. It also focuses on its origin and relationship with the movement sensor as a reference point. The objective is to provide, through the use of technology, a new argumentation about the behavior of the phenomenon, along with a justification for a new use of graphs and the need for Cartesian references. 


\section{The Thematic Workshop and the Study Group}

The spring is the experimental tool for obtaining data, and it was part of the workshop "Movement: I am everywhere, even if you don't see me". There were two movement situations during this workshop: "The spring" and "Build your graph" (Briceño \& Cordero, 2012). The aforementioned workshop was run on various occasions in different settings. This allowed to have different groups with particular characteristics. This paper reports the case of a workshop with a study group made up of 9 youngsters between the ages of 15 and 16 ( 3 female and 6 male) during the First Festival of Communicating Mathematics ${ }^{6}$, which took place in the city of Zacatecas, Mexico. According to the ages of the participants, we can assume that they were secondary school students (In Mexico, secondary school includes students between 13 and 16 years old). This means that it is undeniable that the participants had some knowledge of the topic of graphs and functions, and it is likely that such knowledge may have influenced their interpretations of the task at hand. Nevertheless, our main concern was not to avoid the emergence of scholar arguments in regards to the task, but to analyze how other forms of knowledge appear when scholar restrictions are limited, such as evaluation and the didactical contract. It goes without saying that the social scenario made it possible to have a link of people with scientific knowledge, in which we were more interested in the non-conventional and functional arguments, in case they were to appear.

The analysis took place under a qualitative approach based on participant observation, focused on the productions elaborated by the participants during the workshop. The researcher was responsible for the implementation of the workshops. With the purpose of gathering evidence, the entire workshop session was videotaped. This material, along with the field notes of the researcher in charge and the written productions of the participants, made up such evidence. The videotape of the workshop was fully transcribed. During the process, the analysis of the different sources of data (transcription, field notes and written productions) generated during the session by the group of participants was conducted.

The type of the analysis of data is interpretative and the methodological aspect which guided the gathering of data is related to a theoretical, a priori, analysis in which the initial moments (see "The Spring Situation: Theoretical Foundations and A Priori Analysis") provide a hypothesis about what students might do, and to an a posteriori analysis, which deals with what the students actually did (Buendía \& Cordero, 2005). The analysis was internal and was generated based on the comparison between both analyses resulting in a revisited epistemology of categories, which allowed us to give an account of the planned and implemented situation.

\section{Discussion: A Posteriori Analysis}

The workshop case analysis was divided into three moments: (I) maintenance, (II) crisis, and (III) functionality. The goal of the analysis is to make evident the three vectors established in the theoretical framework as conditions of people's daily lives and for them to express cultural forms of mathematical knowledge obscured in scholastic mathematics.

It is necessary to mention that the analysis of the workshop was possible through video recording. To achieve this, we relied on the video analysis model proposed by Planas (2006).

6 This event was organized by the Annual Congress of Mathematics Education: "Winter School of Mathematics Education", in Mexico. 
This researcher argues that the main objective when analyzing a video is to identify situations of further elaboration of mathematical meanings that occurred under the influence of social interactions. Therefore, it is important to have accurate information on verbal and non-verbal behaviors, and on behavior changes. The reconstruction can manifest itself from a concrete meaning, expressed in a more or less subtle way through verbal or non-verbal behavior.

The six phases that defined our analysis of the video recording of the workshop were:

1. General description of the video. Maintenance, crisis, and functionality sections were detailed according to the three moments marked in our epistemology.

2. Identification of episodes for revision of mathematical meanings. In this phase, episodes that show processes of revision of mathematical meanings were transcribed. These episodes were marked by looking for routine and crisis arguments (according to our theoretical model) regarding the use of graphs in the participants' interventions. These interventions were enclosed from moments of doubt, error, and blocking of the participants. Subsequently, these episodes were entirely transcribed, focusing on the interactions and non-verbal speech expressed by the participants.

3. The search for processes to rework mathematical meanings. In the episodes marked, we analyzed processes in which the participants reworked their arguments, which accounted for the resignification of the use of graphs. In this phase, "routine-crisis" and "crisis-resignification" pairs were created, which configured a way of characterizing knowledge construction processes, or, in our case, resignification.

4. Characterization of social interactions. The mathematical interactions between the participants were reviewed, placing special emphasis on their discourse and physical gestures as a key element to represent mathematical ideas. A first line of argument was proposed about a certain idea that the participants reconstructed in their interaction.

5. Elaboration of explanatory stories. The result of this phase was the construction of stories which gave meaning to the video content, in order to show how such content evolved. In this phase, the participants' interactions and explanations were analyzed along with their written productions and the researcher's field notes with the intention of validating the relationships and meanings constructed by the participants.

6. Comparison of the episodes in the review. In this phase, similarities and differences were sought among the previously proposed explanatory stories. The main idea was to classify the explanatory stories and build categories of resignifications. Furthermore, given that during the workshop the participants were organized in small groups, the reconstructions of each group were compared and differences and similarities were sought among the arguments to generate these categories of resignifications. During this phase, we also carried out the confrontation of the a priori versus the a posteriori analyses.

As we mentioned in phase 4, in order to examine the participants' construction of arguments more deeply, it was necessary to take into account the cognitive, physical, and perceptual resources that people use when facing mathematical ideas. Thus, we took into account an analysis of the different resources used, such as symbolic written communication, oral communication, drawings, gestures, and electronic and physical devices, as well as various types of body movements (Radford et al., 2009). We consider, as does Roth (2001), 
that gestures in conjunction with a wide range of modalities have come to be recognized as key elements in the communication and conceptualization of mathematical ideas.

\section{Maintenance Moment: Search for Invariants and the Permanence of Things which Vary}

The initial activity of the spring situation consisted in drawing the movement of the spring when the weight was placed (see Excerpt $1^{7}$ ). In a general and recurring way, this task gave rise to gesticulations of the participants. That is, gestures occurred in association with discourse (Kendon, 1987 as cited in Vergel, 2015). For example, we named this "the vertical hand" (see Figure 4).

W: Well, the activity we are going to undergo now... is similar to the one you have already finished... but now, it is not going to be with a person [the head of the workshop has a spring with a weight in his hand and shows it to the participants] but with a spring...

W: Now, the question is... let's imagine, well, we don't have to imagine, we have the spring here... and the weight is 50 grams, how should the spring move now?

P: in an upward movement [makes a hand gesture]

Excerpt 1. Initial question and "vertical hand" as gesticulation

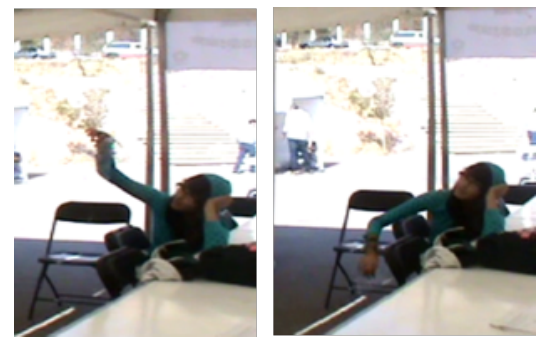

Figure 4. The "vertical hand" Source: Zaldívar (2014)

By this time, the situation generates the first use of the graph of the phenomena through argumentations which use trajectories as the pattern of adjustment. This use is named movement orientation (Use-1). The trajectory does not only refers to the geometric place of the successive positions of the body in motion, but also to the type of interpretation, reading and function of this iconic or gestural pattern in the situation. The functionality (Fu-1) of the graph at this moment of the situation is to indicate direction and sense to the movement, while the form (Fo-1) of the movement is indicated by a certain pattern of adjustment (up

\footnotetext{
${ }^{7}$ The letter $\mathrm{W}$ represents the head of the workshop. That is, the individual responsible for carrying out the activities. P1, P2, P3, .. refer to the different participants engaged in a dialog during the workshop.
} 
and down). The trajectory resignifies space and time in a pattern of adjustment where time is embedded in distance, so variations and trends are not explicitly indicated.

It is noteworthy that at this moment, and with the mentioned use of the graph, there is no explicit reference to the behavior of the system trend. The up and down model seems to establish that the system will stay in perpetual motion. For this reason, it is considered that the argumentation about the behavior of the system caused by the use of graphs is the search for invariants and the permanence of things which vary (Arg-1).

\section{Crisis Moment: Recognition of a Trend Behavior}

The workshop case discussed in this paper differs from other workshops in that it introduced the "Build your Graph" activity before the spring situation. As a consequence, the study group already had a precedent on the use of movement sensors. Consequently, the initial question (see Excerpt 1) was modified (see Excerpt 2).

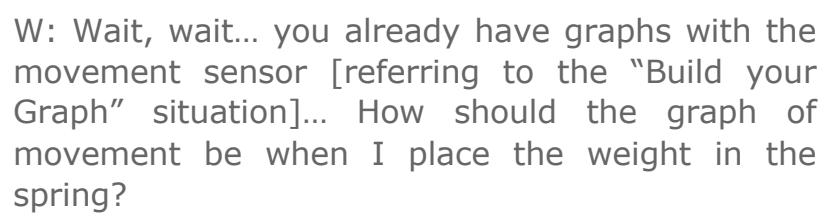

Excerpt 2. Gesture corresponding to the "extended" gesture in the air

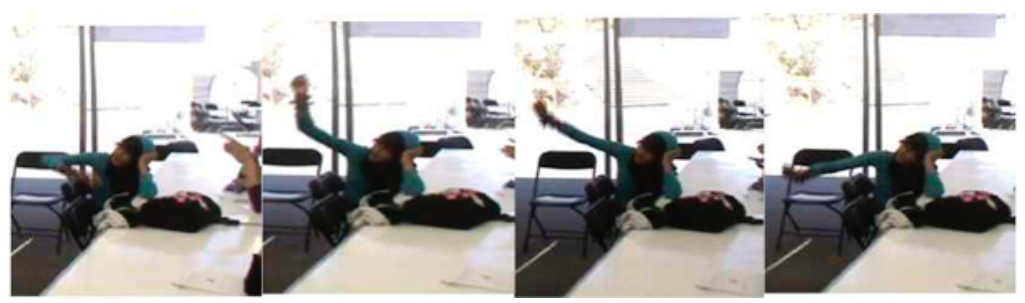

Figure 5. "Extended" gesture in the air Source: Zaldívar, 2014

It is interesting to highlight that the initial gesture of the participant changes when the sensor is considered as reference: she modified the vertical hand and included an extended movement in space (see Figure 5). Therefore, it can be concluded that including the reference point (the sensor as a phenomenological source) gives rise to a crisis in the argumentation used to refer to Use-1 because the visible form of the gesture (up and down) resembles waves, which express a global behavior of the phenomenon. The important thing is how the participant rebuilds the gesture of the vertical hand with a soft sinusoidal movement "extended in the air". Furthermore, the subject identifies that the amplitude of this behavior decreases over time modifying the trend of the system through variation. As a consequence, the use of 
the graph not only refers to movement orientation but also includes a form of how the behavior of the repetitions is and a way to address variation.

This excerpt gives evidence of the reformulation of the trajectory from the explicit requirement of the analysis of the internal structure of the system in terms of the reference point constituted by the sensor. It also allows for the emergence of other arguments, such as variation and trend, which complement the use. This set of arguments caused a crisis in the form (Fo-1) of the graph to interpret movement, space, and make the pass of time explicit, based on the experience produced by the use of the sensor.

This resignification of the use of graphs involves the complexity of the orientation (see Excerpt 3). The production of the team of participants (see Figure 6) highpoints that there is no "need" for an explicit Cartesian axis, but rather to explain the global behavior of the spring over time (without an explicit axis, see Excerpt 3, P3 line). It is important to highlight that the structure and reading of the movement of the system is based on the use of the given graph as orientation; however, it also integrates the variation and trend elements by adjusting the behavior since it incorporates a way to express that the spring will eventually stop (see Excerpt 3, P7 line), and that movement will not be perpetual. For this purpose, they used a pattern of adjustment named curve.

P7: $[. .$.$] because, if it's released... it picks up speed... and$ there it goes... [points out the first part of the curve]

P3: then it... is balanced... [makes a horizontal hand gesture]

P7: because the speed is decreasing and it is stopping...

Excerpt 3. Discussion about variation, trend and emergence of the curve

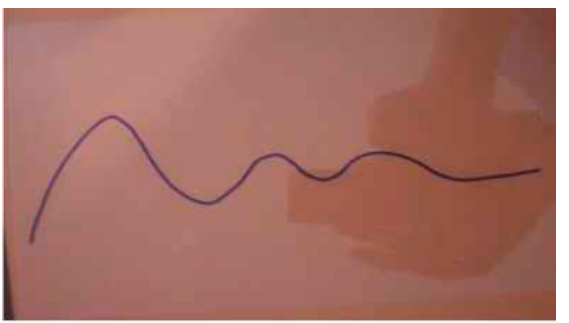

Figure 6. Curve

Despite the fact the orientation is maintained as a use of graphs, other alternative elements were added when the participants were asked if the spring stopped or not. This is expressed in the sensitivity of the characteristics of the element shapes referred to by the participants when they "played" with the visual possibilities in terms of form, size, and descriptions of the representations displayed in their productions (DiSessa et al., 1991; Nemirovsky et al., 1998). An example of this situation is presented in the production of another team (see Excerpt 4 and Figure 7): 
P3: [Holds the spring] It starts speeding up [with the left hand points out the spring and makes an upward and downward movement] and then it goes like this... then it begins to stop...

P3: Did you see? It is getting drowsy... and there it goes with less speed.

Excerpt 4. Does the spring stop?

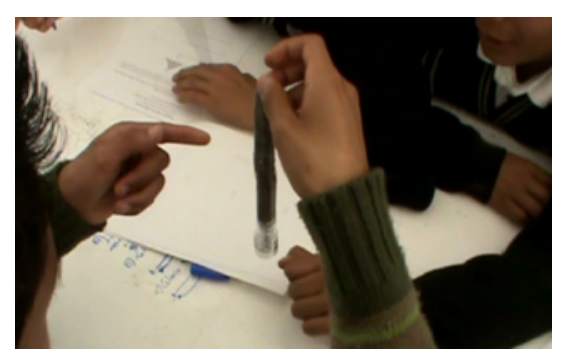

Figure 7. The spring begins to stop Source: Zaldívar (2014)

This team of participants proposed drawing the spring (Figure 8) and, next to it, writing an interpretation of what they understood as the spring gradually stops (Excerpt 4, first comment of P3). They drew several arrows pointing up and others pointing down to suggest direction. The lines become smaller as they move right. When the participants were drawing arrows, their dialog made reference to the size of the lines in a way that indicates that the spring was stopping. They even expressed: "But make them smaller."

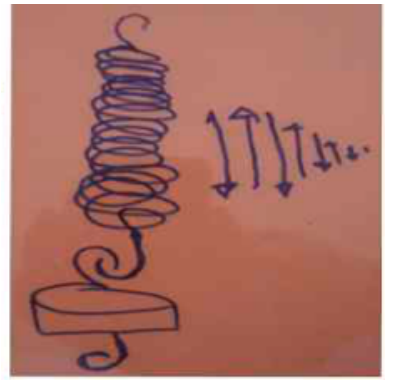

Figure 8. Trajectories with trend Source: Zaldívar (2014)

In this production, orientation was expressed in the trajectory, whereas variation and trend in the "size" of the arrows was expressed in the verbal reference of the phrase "But make them smaller". The passing of time is present in periods characterized by each of the arrows.

There is a resignification of Use- 1 by this moment of the activity. This is not only placed in a representational level but also in an argumentative level. This means that deserting the representational level (as trajectory) could be partial; however, there is an actual development of the level of use. The reference point (citing the sensor) and the need to express that the 
spring stopped, led to the evolution of a more complex Fu-2 of the graph. This is, the graph was used to analyze the variation and trend of the system (Fo-2). This use of the graph was called analysis of the structure (Use-2). It allowed the participants to resignify the argumentation concerning the search for invariants to an explicit argumentation of an asymptotic behavior through the manifestation of the system trend (of the system) (Arg-2), which included the variation and the behavior of the system in a pattern of global adjustment, the curve.

In this way, forcing people's daily lives to anticipate a behavior triggers a crisis in the orientation due to the characteristics of the system. The anticipation is characterized situationally in terms of variation, trend and point of reference. In fact, the second example provides evidence about the resistance in the argumentation of the orientation (at least at a representational level), which permeates the associated use of graphs.

\section{Moment of Functionality: Recognition of an Asymptotic Behavior}

Radford (2009) mentioned that time and space cannot be considered as "pure intuitions", but as cultural conceptual categories and structures constituted from a historical and social web. This assertion is confirmed by the evidence presented in the previous section: the interpretations of the participants' productions are not necessarily Cartesian -even if they drew the Cartesian axis-due to the fact that their readings also attended the need of orientation, but added elements that promote a global overview of the behavior. For this reason, the reading and interpretation of graphics cannot be taken as a trivial task.

After the establishment of the maintenance crisis (the search for invariants and the permanence of things that vary), the goal of the following activities was to keep the alternative argumentations elaborated by the study group and described in the former section. Hence, such activities promoted adjustments to the established patterns in order to anticipate the shape of the graph. For this purpose, the Cartesian references were made through local analysis. As a consequence, the arguments of trend focused more on an asymptotic behavior (see Figure 9) based on recognizing that the "straight line" is the graphical behavior which expresses the final form of the curve after a period of time (Excerpt 5, line 11). For example:

P1: in this part... [points out the higher part of the curve in Figure 6] when the weight is placed it goes up, because it is like grabbing the weight... of...

P1: The weight goes... and then, its position is constant, starts going down... until it is like this... [Makes a hand gesture drawing a horizontal line in the air]

Excerpt 5. The straight line as an asymptotic pattern of adjustment 


\section{$2 \mathrm{E}$}

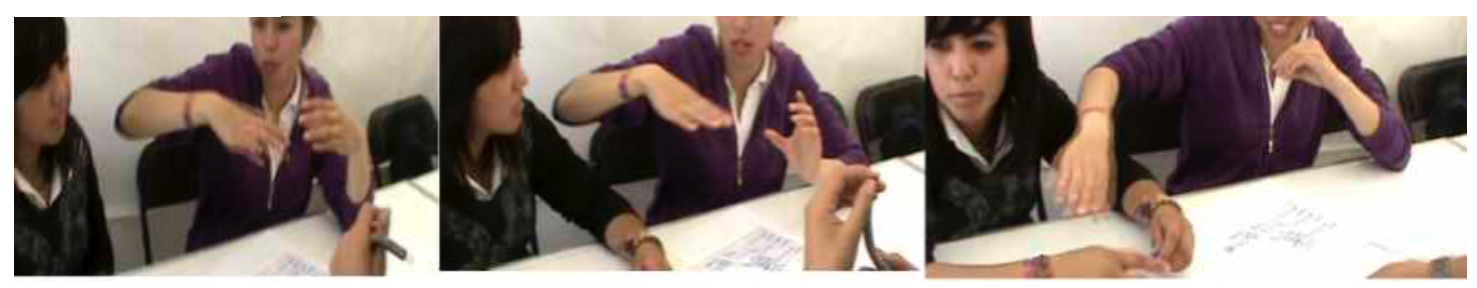

Figure 9. Asymptotic pattern

Source: Zaldívar (2014)

The straight line as a model of asymptotic trend evolves as a behavior associated to the phenomenon based on the argumentations, but it is also expressed with the "horizontal" hand gestures. The argumentation elaborated is connected to behavior which does not "contain" unusual forms, but remains for a long time. It will also become another graph sometime in the future (Arg-3). This means that asymptotic emerges in terms not just of behavior without abrupt changes, but with trends.

At this moment of alternative maintenance or functionality, the participants discussed the Cartesian elements produced by a local analysis of the initial conditions of the system, which takes the Cartesian origin as a reference point.

W: ... Would there be any difference in the graph if you released it like this? [recreates the weight releasing it without stretching the spring ]...

W: Would the graph be different if I released it like this? ... or if I pulled and dropped? [recreates this movement from below, stretching the spring and then releasing it].

P7: Yes... the amplitude.

W: If there is a difference, what could it be?

P1: the origin...

P1: It would be like this in the graph... and then it would go up like this... and then like this... [recreates the movement making gestures of a curve in the air starting from the bottom and going up, and then down again]

Excerpt 6. Discussion of the initial conditions and the Cartesian origin

The evidence shows a reformulation of the curve. At this moment, the functionality of the use of the graph is to anticipate the behavior (Fu-3). This causes the emergence of other elements, which should be controlled by the participants in order to show the behavior over time and to propose a pattern of adjustment which indicates trend and elements of reference such as the Cartesian origin (Fo-3) such as amplitude, height, trend, and perceived form. Thereupon, the elements of crisis, anticipation and local analysis trigger the use of the graph expressed in the analysis of behavior (Use-3) and cause the emergence of Cartesian elements, which also cause an argumentation of the system referred to as asymptotic behavior (Arg-3). 


\section{Concluding Remarks}

\section{About the use of graphs and the maintenance and crisis argumentations}

The unit on analysis, the use of graphs, revealed functionalities and forms used by the study group to deal with and answer the activities of the spring situation. Furthermore, the analysis showed that the arguments regarding variation, trend and analysis of the reference point (the origin) allowed for the emergence of other functionalities and forms that are not used a priori. The theoretical advance presented in this paper aided in comprehending that the analysis of situational argumentations which lead to crisis in maintenance argumentations sheds light on the development of the use of knowledge through its functionalities and forms. This is an innovative element of the research. People's daily lives, as an auxiliary theoretical element, made it possible to establish a relationship between the use of knowledge in a specific situation and the argumentations that are resignified in the process and how it can be done.

The identification of maintenance crisis or breakups determined the maintenance argumentations. This means that the way the system changed and its trends (Fu-2) can be explained in terms of the cultural forms of daily life used to refer to the behavior of the system through patterns of initial adjustments, specifically between the up and down patterns of adjustments (Fo-1), and the need to figure out the permanence and determine invariants in things which vary. The structure of the pattern of adjustment becomes more complex, giving rise to a form that expresses global-trend (Fo-2). However, the inclusion of the movement sensor as a reference point, opened the possibility of incorporating the Cartesian elements to the curve (Fo-3) and, then, anticipated the behavior of the system (Fu-3). Therefore, the initial argumentations which look for permanence and invariants in things which vary in the system are resignified from the specific institutional experience of the spring situation to an argumentation in which the asymptotic behavior emerges. The result is a trend behavior to a horizontal line.

Figure 10 shows a reference framework that synthesizes the results of the use of graphs and the argumentations of people's daily lives regarding the situation of the spring based on the evidence. 


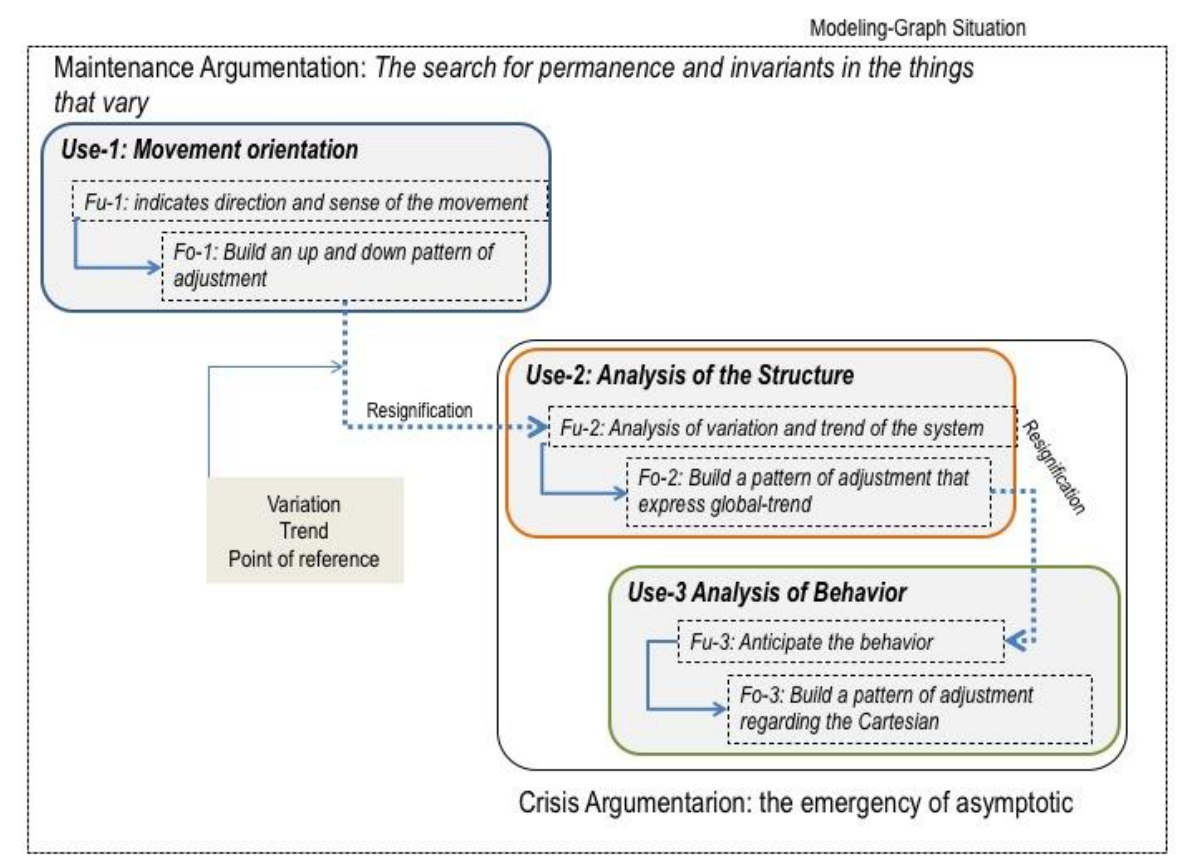

Figure 10. Argumentative framework of the spring Source: Own elaboration

This frame of arguments problematizes the graph from its use in a specific situation. The results highlight the importance of the emergence of argumentations focused on trend, variation and recognition of reference points (such as the origin) to interpret and read the Cartesian graph seen as a mathematical object. People's daily lives, as a theoretical category of the research, suggest that the patterns of adjustment (such as trajectory and curve) could be considered as predecessors and an emergent culture of the Cartesian graph that makes the resignification possible. Subordinating the Cartesian graph to the trajectory and suppressing this in school could continue generating difficulties in the interpretation, reading and construction of graphs, as evidenced in the works of Leinhardt et al., (1990) among others.

\section{The Function of Daily Lives: Recovering the Cultural Forms of Knowledge}

The results obtained so far show that daily lives, through M-G, generate argumentations which rely on the comprehension of actions. For this reason, orientation through patterns of adjustment focused on trajectories constitutes the functional base of the uses of the generated graphs. In other words, the evidence suggests that the search for permanence and invariants in things which vary is part of the human activity regarding a signification of the movement that the study group brings into play in a specific situation. That is, it constitutes the matter intended to maintain. However, this function is obscured in the smd due to the fact that the pair "orientation-trajectory" in scholastic mathematics carries a pejorative connotation and is 


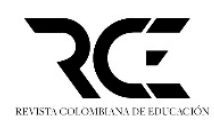

subordinated to the Cartesian graph. This could be an effect of the centralization in the concept of function, regardless of people's resignification of movement from orientation.

The epistemology of people's daily lives based on the maintenance-crisis mechanism made it possible to problematize people's knowledge and generated resignifications in a progressive and intentional way. Variation, trend, and construction of a reference point are not explicit arguments embedded in the maintenance arguments of daily life. They are constituted and materialized after a crisis. They occur as an emergent culture. It seems as if perception were not enough, and these arguments needed progressive resignifications and the development of more complex tools. In this way, the model of initial permanence becomes a model of asymptotic behavior by problematizing the speed of trend and its variation. Furthermore, the patterns of adjustment become more complex not just from the representational level of moving from trajectories and curves to Cartesian, but from a more visible resignification level. Based on the theoretical considerations, it can be said that the representations give an idea on a figural level; however, the use allows for expressions in an argumentative level. This indicates that the search for permanence and invariants in things which vary through orientation is a cultural form and constitutes the daily lives of people.

Finally, the emphasis placed on "people" responds to the consideration that the didactic task should not be focused only on people in school (school-aged children and youngsters). It should be carried out with everyone, current, and future citizens (Chevallard, 2013). Without any doubt, the interest in the use of mathematical knowledge is not only focused on how youngsters use mathematical knowledge in school settings but also on promoting the understanding of how people use mathematics in working situations, in daily life, or in different settings.

\section{References}

Arnay, J. (1997). Reflexiones para un debate sobre la construcción del conocimiento en la escuela: Hacia una cultura científica escolar. [Reflections for a debate on the construction of knowledge in school: Towards a school scientific culture] In M. A. Rodrigo and J. Arnay (Comps.), La construcción del conocimiento escolar (pp. 30-45). Paidós.

Berger, P. and Luckmann, T. (1991). The social construction of reality: A treatise in the sociology of knowledge. Penguin Books.

Buendía, G. and Cordero, F. (2005). Prediction and the periodical aspect as generators of knowledge in a social practice framework. Educational Studies in Mathematics, 58, 299333.

Buendía, G. and Montiel, G. (2011). From history to research in mathematics education: Socioepistemological elements for trigonometric functions. In V. Katz and C. Tzanakis (Eds.), Recent developments on introducing a historical dimension in mathematics education (pp. 67-82). MMA Notes.

Cantoral, R. (2013). Teoría socioepistemológica de la matemática educativa: Estudios sobre construcción social del conocimiento. [Socioepistemology theory in mathematics education: Research on social construction of knowledge]. Editorial Gedisa. 
Cantoral, R. and Farfán, R. (2003). Mathematics education: A vision of its evolution. Educational Studies in Mathematics, 53(3), 255-270.

Cantoral, R., Moreno-Durazo, A. and Caballero-Pérez, M. (2018). Socio-epistemological research on mathematical modelling: An empirical approach to teaching and learning. ZDM, 50, 77-89.

Chevallard, Y. (2013). Enseñar matemáticas en la sociedad del mañana: Alegato a favor de un contraparadigma emergente. [Teaching mathematics in tomorrow's society: Plea in favor of an emerging counter-paradigm]. Journal of Research in Mathematics Education, 2(2), 161-182.

Civil, M. (2002). Everyday mathematics, mathematicians' mathematics, and school mathematics: Can we bring them together? In M. E. Brenner and J. N. Moschkovich (Eds.), Everyday and Academic Mathematics in the Classroom (pp. 40-62). The National Council of Teachers of Mathematics [NCTM].

Cordero, F. (2008). El uso de las gráficas en el discurso del cálculo escolar: Una visión socioepistemológica. [The use of graphs in the school mathematical discourse. A Socioepistemoly vision]. In R. Cantoral, O. Covián, R. M. Farfán, J. Lezama and A. Romo (Ed.), Investigaciones sobre enseñanza y aprendizaje de las matemáticas: Un reporte iberoamericano (pp. 285-309). Díaz de Santos-Comité Latinoamericano de Matemática Educativa.

Cordero, F., Cen, C. and Suárez, L. (2010). Los funcionamientos y formas de las gráficas en los libros de texto: una práctica institucional en el bachillerato. [The functionality and form of graphics in textbooks: A high-school institutional practice]. Revista Latinoamericana de Investigación en Matemática Educativa, 13(2), 187-214.

Cordero, F., Gómez, K., Silva, H. \& Soto, D. (2015). El discurso matemático escolar: adherencia, exclusion y opacidad. [The school mathematical discourse: Adherence, exclusion and opacity]. Gedisa.

Cordero, F. (2016). Modelación, funcionalidad y multidisciplinaridad: el eslabón de la matemática y el cotidiano [Modeling, functionality and multidisciplinarity: The link of mathematics and everyday life]. In J. Arrieta and L. Díaz (Eds.), Investigaciones latinoamericanas de modelación de la matemática educativa (pp. 59-88). Gedisa.

DiSessa, A., Hammer, D. and Sherin, B. (1991). Inventing graphing: Meta-representational expertise in children. Journal of Mathematical Behavior, 10, 117-160.

Hoyles, C., Noss, R. and Pozzi, S. (2001). Proportional reasoning in Nursing practice. Journal for Research in Mathematics Education, 32(1), 4-27.

Lave, J. (1988). Cognition in practice: Mind, mathematics and culture in everyday life. Cambridge University Press.

Leinhardt, G.; Zaslavsky, O. and Stein, M. (1990). Functions graphs and graphing: Tasks, Learning and Teaching. Review of Educational Research, 60(1), 1-64.

Moschkovich, J. (2002). An introduction to examining everyday and academic mathematical practices. In M. E. Brenner and J. M. Moschkovich (Eds.), Everyday and Academic mathematics in the classroom (pp. 1-11). The National Council of Teachers of Mathematics [nctm].

Nemirovsky, R. Tierney, C. and Tracy, W. (1998). Body and graphing. Cognition and Instruction, 16(2), 119-172. 
Nunes, T., Schliemann, A. andCarraher, D. (1993). Street mathematics and school mathematics. Cambridge University Press.

Planas, N. (2006). Modelo de análisis de videos para el estudio de procesos de construcción de conocimiento matemático. Educación Matemática, 18(1), 37-72.

Pozzi, S., Noss, R., and Hoyles, C. (1998). Tools in practice, mathematics in use. Educational Studies in Mathematics, 36, 105-122.

Radford, L. (2009). Signifying relative motion: Time, space and the semiotics of cartesian graphs. In W. M. Roth (Ed.), Mathematical representation at the interface of body and culture (pp. 45-69). Information Age Publishing.

Radford, L. (2013). Three key concepts of the theory of objectification: Knowledge, knowing, and learning. Journal of Research in Mathematics Education, 2(1), 7-44.

Radford, L. (2014). Un recorrido a través de la teoría de la objetivación. In S. Takeko and L. Radford (Comps.), Teoria da objetivação: fundamentos e aplicações para o ensino e aprendizagem de ciências e matemática. Editora Livraria da Física.

Radford, L., Edwards, L., and Arzarello, F. (2009). Introduction: Beyond words. Educational Studies in Mathematics, 70, 91-95.

Rodrigo, M. J. (1997). El hombre de la calle, el científico y el alumno: ¿un solo constructivismo 0 tres? [The man in the street, the scientist and the student: A single constructivism or three?]. Novedades Educativas, 76, 59-65.

Roqueplo, P. (1974). Le partage du savior. Science, culture, vulgarization. Seuil.

Roth, W.-M. (2001). Gestures: Their role in teaching and learning. Review of Educational Research, 71(3), 365-392.

Slater, E., Morris, J., and McKinnon, D. (2018). Astronomy alternative conceptions in preadolescent students in Western Australia. International Journal of Science Education, 40(17), 2158-2180.

Soto, D. and Cantoral, R. (2014). Discurso matemático escolar y exclusión: Una visión socioepistemológica [School Mathematical Discourse and exclusion. A socioepistemological vision]. Boletim de Educação Matemática, Rio Claro, 28(50), 1525-1544.

Suárez, L. and Cordero, F. (2010). Modelación-graficación, una categoría para la matemática escolar: Resultados de un estudio socioepistemológico [Modeling-graphing, a category for school mathematics: Results of a socioepistemological study]. Revista Latinoamericana de Investigación en Matemática Educativa, 13(4-II), 319-333.

Tuyub, I. and Cantoral, R. (2012). Construcción social del conocimiento matemático durante la obtención de genes en una práctica toxicológica [Social construction of mathematical knowledge during the obtaining of genes in a toxicological context]. Boletim de Educaçao Matemática, 26, 311-328.

Zaldívar, D. (2014). Un estudio de la resignificación del conocimiento matemático del ciudadano en un escenario no escolar (Unpublished doctoral dissertation). Centro de Investigación y de Estudios Avanzados del Instituto Politécnico Nacional, México. 